\title{
Subculturas visuales y la intervención urbana. Santiago de Chile 1983-1987
}

\author{
Visual Subcultures and City Intervention. Santiago, \\ Chile, 1987-1983
}

\author{
Elizabeth Munsell \\ Universidad de Chile \\ lizmunsell@gmail.com
}

\begin{abstract}
Resumen:
En los años ochenta, surgió un discurso de resistencia por parte de una visualidad emergente en Chile. Cuando una cultura cada vez más visual y mediática fue potenciada por el gobierno militar como aparato ideológico del capitalismo neoliberal. En respuesta, jóvenes subculturales desmontaron las representaciones visuales de la cultura dominante a través de medios visuales de comunicación no mass-mediatizados. Las subculturas resultantes de un contacto aumentado con el extranjero no asumieron pasivamente la cultura de masas pop importada, sino que desarrollaban sus críticas de la cultura visual dominante y del gobierno militar mediante una visualidad marcada, difundiendo sus prácticas culturales híbridas e identidades alterables en el espacio público santiaguino de alta conectividad.
\end{abstract}

Palabras clave: subcultura, cultura visual, post-representación, disidencia estética.

\begin{abstract}
:
A resistance discourse parts from an emergent visuality during the eighties in Chile, when a gradually more visual and mediatized cultural is fostered by the military government as an ideological apparatus of neoliberal capitalism. In response, subcultural youth dismantled the dominant culture's visual representations using non-mass-mediatized visual communications mediums. The subculturas that resulted from an increased contact with foreign countries did not passively assume the imported pop culture, but rather developed their critiques of the dominant visual culture and the military government through their distinct visuality, disseminating their cultural practices y alterable identities in Santiago's public space of high connectivity.
\end{abstract}


Key-words: subculture, visual culture, post-representation, aesthetic dissidence.

\section{Cultura visual dominante y visualidad subcultural}

A lo largo de los años ochenta, en Santiago de Chile emerge una escritura prohibida y anónima que toma las paredes de la ciudad como lugar de inscripción. Debe entenderse que es a partir de la histórica práctica chilena de manifestarse políticamente a través de la expresión visual en el espacio público, que surge la producción de estos nuevos textos culturales subversivos. Esto, en un contexto con altos niveles de censura y exclusión instaurados por el gobierno militar al que se adhieren cambios en los modos de expresión e identidad de los individuos, a partir de la introducción del modelo económico neoliberal. Mientras la tradición de utilizar el espacio público con fines políticos abundaba en el Chile previo al '73, la recuperación de esta práctica en los ochenta responde a nuevas pautas de representación no calculables por los parámetros políticos de luchas anteriores, siendo esta vez pertenecientes a una generación portadora de una hibridación de lo local por la influencia de las subculturas de llegada.

La investigación considera un movimiento underground suelto e inorgánico, con el fin de examinar uno de las prácticas comunicacionales ensayadas por algunos de sus integrantes. La construcción de esta escena paralela, discrepa de la cultura militar dominante y del movimiento de la oposición, corresponde al desarrollo de prácticas artísticas y culturales que no fueron fácilmente categorizadas bajo antiguas pautas de representación estética ni política. Estas subjetividades que se oponían a la dominación ideológica de cualquier índice institucional, se deben entender dentro del contexto de la desterritorialización de sus referencias culturales permitidas por aperturas económicas y mass-comunicacionales difusas, más las condiciones sociopolíticas del autoritarismo que se encontraron.

Los integrantes de las subculturas examinadas aquí son los fundadores santiaguinos de la actitud de "no pescar a nadie", la cual señalaba el abandono de la política partidista que encarnará la juventud de las décadas siguientes. Las expresiones estéticas características de estas "tribus" tempranas, asumían connotaciones políticas en el contexto de dictadura -son postuladas como una propuesta de resistencia en contra de la censura, la autocensura y los dogmatismos reguladores del comportamiento social. Los creadores de esta estética de disidencia desarticulada, simbolizaban cambios en el clima cultural de los ochenta, al exento de que su estilo inicialmente marginal se instauró como moda juvenil masiva a mediados de la década. Más que organizarse políticamente en torno a las protestas por la democracia -aunque también participaban en manifestaciones y algunas en barricadas- 
estas figuras germinaron una presencia cultural notable en el ámbito metropolitano, la cual pretendía señalar su oposición a la política autoritaria a través de expresiones estéticas desviadas. Mientras tales expresiones culturales tomaban múltiples cuerpos mediáticos y artísticos -revistas clandestinas, la música punk, pop y rock, la pintura, el graffiti, los cómics, el performance y el arte de acción-aquí se enfoca en el uso de la pared como medio comunicacional desinstitucionalizado.

Al estirar el medio de la escritura en la pared más allá de la función política que cargaba hasta entonces, los sujetos escritores de rayados ponen en crisis el estatuto de la representación desplegado en el espacio público. Curiosamente, en el acto de exteriorizarse a través de una escritura (des)territorializada, los escritores y sus escritos se vuelven impresentables al ojo amansado; sus gestos desafiantes revelan una resistencia despolitizada que rechaza normas de inscripción política y conducta social. De igual forma, el uso de prendas fosforescentes y cortes de pelos punk en medio de un paisaje repetidamente descrito como gris, se planteó como táctica de provocación a un pueblo disciplinado por años de dominio autoritario. El mensaje de esta comunicación intencional nunca fue concretizado por emisor ni destinatario, pues pretendía intervenir la visualidad para desorientar la vista del receptor momentáneamente, destacando así el telón de fondo de toda construcción de lo normal en la vía pública.

Respecto a las múltiples formas de pensar lo político que tenían estos sujetos históricos -en relación a la pendiente crisis de representación política de los años 80 o no- en retrospectiva distanciada podemos plantear como hipótesis que estas nuevas subjetividades en construcción, se expresaban a través de una visualidad emergente que se difundía de manera no mediatizada en el espacio citadino; en esta transgresión de los medios de comunicación institucionales, se permite desplegar una fragmentación emancipatoria que se experimenta en la posibilidad de (auto)mediatizar y hacer circular toda expresión a través de lo visual. De manera subliminal y performativa, la agencia (social, cultural, política) se desplaza por una visualidad difusa.

Al entrar a la cultura visual global, no sólo las culturas dominantes militar/neoliberal se mass-mediatizan y se visibilizan en el paisaje urbano, sino también y cada vez más, los cuerpos resistentes a tales procesos de homogenización, recurren a lo estético como medio significativo. Si bien la norma social citadina, se constituye por la apariencia de imágenes, su poder de reproducirse y la invisibilización de su propia autoría, podemos atribuir a la visualidad un potencial transformador de deshacer los límites culturales de lo posible. Debido al carácter no consolidado de los procesos visuales de significación, en sus puntos infinitos de conectividad y sublimación, lo visual deja de ser un mero medio de transmisión ideológica sin costuras, y deviene como sitio de estallido y construcción de nuevas subjetividades y afectos híbridos. La representación en su sentido mimético se 
desplaza por la provocación desorientadora de la imagen propia y la reproducción a mano inédita de la palabra en la intemperie.

En contraste con los murales o pintados políticos de fines partidistas que también empiezan resurgir a principios de los ochenta, los escritos en la pared que integran el objeto de este estudio pertenecen a la categoría "graffitis de leyenda", término acuñado por Claudia Kozak en su estudio de graffitis argentinos Contra la pared. Kozak clasifica estos rayados como frases para leer que "no están respaldadas por institución alguna (agrupación o partido político, por ejemplo) y muy habitualmente, y por el contrario, evidencian un fuerte carácter anti institucional” (2004, p. 27). Al diferenciarse de otros signos en la superficie de la ciudad que privilegian el contenido de la representación y designan los recursos materiales como medios transparentes, los rayados que emergen en los ochenta ponen en cuestión las relaciones cotidianas con el lenguaje. Su presencia hecha a mano interrumpe la visualidad pulida de los anuncios publicitarios y expone el intento didáctico de los pintados políticos. La falta de un contenido directo expuesto en estos textos indica no sólo el agotamiento de ideologías políticas utópicas, sino también la inauguración de una sociedad globo-mecantil en la que su alcance mediatizado de materialidades extranjeras corresponde al vaciamiento de la subjetividad -particularmente en las generaciones crecidas en dictadura-. Esta fisura en la representación de sujetos e ideales, anteriormente expresados por partidos políticos e identidades nacionales, se desarrolla en los ochenta con la creciente entrada de productos e identidades (sub)culturales a través del mercado neoliberal. Para Slavoj Žižek, "el 'agotamiento' del Estado nación tradicional basado en la noción del ciudadano abstracto identificado con el orden legal constitucional", se debe en parte a "los múltiples vínculos transnacionales, desde el capital multinacional hasta los carteles de la mafia y las comunidades políticas interestatales" (2003, p. 8). El interés en la capacidad comunicativa del lenguaje se colapsa por los escritores en la pared, al rayar no para anunciar algo, ni para revelar la subjetividad ideológica detrás de los signos, sino para ocupar un lugar en un espacio de alta conectividad.

Este auge por los escritos en las paredes no sólo se produce en el Chile de los años ochenta, sino en todas las grandes metrópolis latinoamericanas, fenómeno designado como "el tercer gran momento contemporáneo del graffiti, luego de París del '68 y New York de los años setenta" por el semiólogo colombiano Armando Silva, quien afirma además que "al comparar luego su ambiente iconográfico con el de las europeas o norteamericanas, pudimos comprender por qué la dicción graffiti de los años ochenta adquiere su mayor resonancia, expresividad y novedad en las urbes de este Continente" (1987, p. 16). Silva apunta al desarrollo de nuevas estrategias de hacer política que escapan a los formatos representativos de partidos e ideologías: "la circunstancia particular de recortes en la expresión ciudadana por parte de algunos de sus gobiernos, hace que el 
graffiti en Latinoamérica pueda aceptarse como otra fuente de opinión pública” (1987, p. 17). Al referenciar las definiciones del graffiti proveídas en los textos ya mencionados, aquí elaboramos el concepto acorde a su función social: el graffiti se define como una "escritura de lo prohibido" cuya inscripción implica tres niveles de trasgresión -la enunciación desde la marginalidad (la digresión del ordenamiento jerárquico de poderes expresivos y participativos), la desterritorialización de la escritura (la confrontación de la ciudad letrada con los medios de legitimación de aquel orden), y la recuperación del espacio para fines particulares (rechazo del derecho supremo a la propiedad privada). A los graffitis de estilo leyenda examinados aquí, pueden ser añadidas dos formas adicionales de trasgresión: el desdibujar de los límites y formatos establecidos por los pintados políticos, y finalmente, la desideologización de lo político que corresponde a su visualización.

La dificultad que implica el acercarse a un objeto tan marginal, en cuanto a su valorización dentro del campo de producción cultural -sin tener que mencionar la maquinaria ideológica proporcionada por la prensa que calcifica, sin profundizar, el graffiti como delincuencia-, se intensifica por las condiciones de anonimato y fugacidad en que dicha práctica se lleva a cabo. Por el hecho de revelarse a través de temporalidades y lenguajes no institucionalizados, el graffiti tiende a perder gran parte de su (no)sentido cuando desde el mismo momento en que sale del cuerpo ya se ha vuelto pasado. Esto demuestra una fuerte resistencia a "la conversión de [su] experiencia en un producto terminado" (1987, p. 54), precisamente por mantenerse fuera de las pautas tradiciones de representación, quedando de esta manera como invasión misteriosa, concretizada sólo en huellas y susurros.

Silva enfatiza este componente del proceso (versus el producto) y el gesto (versus la concretización), relacionado con el mensaje que se inscribe:

El graffiti es una escritura que, al situarse del lado de la prohibición social, realza, de manera peculiar, la acción que la ejecuta. Quien elabora sus trazos los realiza concibiendo los signos de un mensaje, pero al mismo tiempo adelanta un recorrido físico y mental.... El graffiti se escribe en movimiento, digamos, y por ello pensamos en una acción que ejecuta una escritura o, si se quiere, un tipo de escritura cualificado por la acción. (1987, p. 19)

Lo que da peso a los rayados no es su factor articulador, sino la evidencia de haberse atrevido a escribir, destacando la experiencia del acto más que la significación final.

Si bien el sujeto sólo puede tener lugar a través de la representación, este puesto se pone en crisis por los escritores de graffiti que niegan la construcción histórica de sus subjetividades. Al desorientarse de los escenarios tradicionales de la representación, rehusando la firma, el registro y la finalización de su obra, se suele desobjetivar no sólo el sujeto responsable por el acto de la inscripción, sino también la evidencia de haber pasado. Sin embargo, como hemos visto en la visualidad contemporánea de la ciudad, el estallido 
de la escritura en la pared se ha vuelto fenómeno inédito. En este sentido, el graffiti es un medio que establece el lugar de un sujeto impresentable a través de la territorialidad en el espacio público. Corresponde al deseo de expresarse a pesar de las barreras -y medios establecidos- de comunicación posible; el propósito de esta forma de expresión es la conectividad a través de lo visual, no la translación de un mensaje o ideal. Así ocurre en la esfera relacional, término explorado por Nicolás Bourriaud, para el medio del graffiti:

El espacio en el que las obras se despliegan es el de la interacción, el de la apertura que inaugura el diálogo ...Las obras producen espacio-tiempos relacionales, experiencias interhumanas que tratan de liberarse de las obligaciones de la ideología de la comunicación de masas, de los espacios en los que se elaboran. (2006, p. 53)

Si bien estas obras demandan la reflexividad del espectador por hacer evidente sus recursos lingüísticos -confrontándole con los mecanismos que filtran y dan forma al contenido- esta reflexividad se confronta al agotamiento ideológico, en el cual la eliminación de la posibilidad de entregarse a la imagen resulta el estancamiento del espectador. Ocurre un vaciamiento de la subjetividad frente a la incapacidad de engancharse, emocional o ideológicamente, al significado y/o punctum de un mensaje. La obstrucción de conectividad entre referente y receptor se disipa en la reproducción continua de la imagen o palabra que alivia el peso de la representación a través de su proliferación inédita. Hal Foster, sin embargo, señala que la repetición opera como alivio de la intensidad del trauma de la imagen, exagerando al mismo tiempo lo traumático del contenido. El concepto del realismo traumático desarrollado por Foster, destaca una imagen que puede ser "conectada $y$ descontectada, afectiva $y$ sin efecto, crítica $y$ conforme" (1996, p. 130). En la cultura visual se crea un efecto vacío por la repetición, tanto como un feeling de sobresaturación incontenible.

En el caso de pop art discutido por Foster, tanto como para el graffiti, la toma de posición dentro del escenario de la cultura de consumo no es la entrega a su sistema de valorización, sino la apropiación y subversión de su herramienta principal de seducción una visualidad difusa-. Mientras hoy el graffiti puede perder su fuerza agitante en este escenario, desbordándose su coeficiente crítico, todavía se ubica en su capacidad de confirmar su presencia a través de una reproducción que interrumpe fuerzas hegemónicas en juego, aún coincidiendo con algunas. El propósito no es ya contestar un orden político a través de la representación de ideologías en oposición, sino hacerse visible. Esta táctica reconoce que en las culturas altamente mediatizadas, lo que se ve en los medios de difusión se establece como realidad. En este sentido, la creación de "cambios en sensibilidades colectivas" también se hace por la mediatización de imágenes sobre la base de lo cotidiano, que parece ser hoy un terreno mucho más fértil que la 'cultura popular', 
forma que sólo existe en oposición a la 'alta cultura' y a raíz de ella” (2006, p. 53). La consolidación del capitalismo transnacional homogenizante, irónicamente permite una diversidad fragmentaria de sujetos cuyos recursos creativos parecen tan inagotables como las maquinarias ideológicas de la cultura visual.

\section{Escritura y espacio (des)dibujados}

La desterritorialización de la identidad que ocurre a través de las llegadas del extranjero contribuye al sentido de fragmentación y desconexión experimentado en un espacio de conectividad aumentada, pero altamente regulado por la censura. Al mismo tiempo, estas brechas de experiencia permiten la emergencia de una cantidad de identidades inédita, reflejadas en las subculturas de jóvenes. En una entrevista con la Revista de Crítica Cultural, el miembro del colectivo Los Ánjeles Negros (sic) Gonzalo Rabanal, admite que:

... de alguna manera la dictadura creó las condiciones para que nosotros pudiéramos operar con ella; elaboró un paisaje que nos acogió en toda su miseria y brutalidad... Aquí, todos los indocumentados, sean 'cumas', 'patos malos', 'maracas', 'travestis', punki, thrash, entran a convivir dentro de esta franja negra, dentro de este espacio Frankenstein que le da cabida a todas las minorías. (Moreno, 2004, p. 35)

Al pertenecer a la esfera de contenidos repetidamente borrados, los graffitis hacen emerger la posición marginal como parte esencial de su operación. Los años ochenta encarnan una etapa en la cual el movimiento juvenil, sea organizado y articulado políticamente o disperso y subterráneo, busca "una nueva estrategia comunicativa de amplios alcances en diferentes sectores marginales” (Silva, 1987, p. 22). La recuperación de la práctica de rayar la pared en Santiago responde a un momento de moderado alivio de la violencia practicada de manera sistemática en los años inmediatamente siguientes al golpe. Sin embargo, la búsqueda de salidas de expresión se realiza bajo condiciones impuestas por la dictadura -o "dictablanda" como algunas personas la empiezan a denominar en esta etapa-, condiciones que cuentan con: la construcción de nuevas visualidades en el paisaje urbano, el aumento de publicidad y el desarrollo urbano ejemplificado por el desplazamiento de ciertas poblaciones centrales hacia la periferia de la ciudad, y las modernizaciones, o mejor dicho privatizaciones, de instituciones y terrenos antes públicos. Si bien se ve disminuida en gran cantidad la táctica política de la desaparición, la dictablanda recurrió a otros modos de dominación ideológica convocados en el plano visual. Estos se articulan a través de un ordenamiento autoritario y capitalista del espacio urbano cuyo eje fundamental es el borrado (de la vista) de la pobreza y la promesa de una 
felicidad comprada, representada por el sueño norteamericano de la clase media, el cual se vio expandido a través de los medios (radio y televisión) y los carteles publicitarios ${ }^{1}$.

Ya entrada la década de los ochenta, la reproducción de una estética cuyas influencias principales encuentran sus orígenes en la cultura folklórica previa al golpe se complica por la mass-mediación de producción cultural extranjera y su recepción por parte de muchos jóvenes que no comparten lo apremiante de seguir desarrollando la línea propiamente chilena. Emerge entonces una generación crecida en dictadura y con pocos recuerdos de otros tiempos. En una entrevista para la revista La Bicicleta, en abril de 1986, el joven bajista Daniel Puente relata:

... uno no tiene memoria para atrás, los viejos tampoco hablan de eso, ellos vivían otra época súper distinta. Me han contado que antes del 73 había colores, gente hippie, y fumaban todos pitos en la calle, había otra onda, un relax. Y ahora nosotros somos únicos, nadie nos cuenta, no tenemos memoria, somos únicos dentro de un sistema súper represivo, pero igual estamos acá, vivos. (1986, p.3)

Aunque vehementemente anti-pinochetista, la falta de dirección y de manifiesto político de muchos jóvenes de esta generación los regula en la categorización de una(s) subcultura(s); este término se diferencia de la noción de la contracultura que encarnaron las generaciones anteriores ligadas al movimiento nacional por el socialismo. A principios de los ochenta, el plano cultural de la oposición se vio dominado por la música popular y el teatro independiente, ambos portadores de la tradición izquierdista (Rivera, 1982, p. 96). Surge entonces una generación que se caracteriza por un desinterés en (o en desconocimiento del) pasado y el deseo de bailar (algo que no se hacía en las peñas del canto nuevo). Mucho menos traumatizados por los crímenes de la dictadura, para ellos el elemento más presente de la política social autoritaria es el toque de queda y la agresión policial en la calle. En oposición directa a tales circunstancias, se desarrolla una cultura callejera, encarnada por los punks, new waves y otros jóvenes marginales que se juntan y relacionan en las plazas y esquinas.

La expresión a través de lo visual y el rechazo de la ideología política se ve manifestada por estos grupos subculturales, cuyo enfoque político no-partidista es simplemente el fin del autoritarismo en su país, y no necesariamente la articulación de una crítica en contra

\footnotetext{
${ }^{1}$ Durante los ochentas el espacio físico de Santiago se re-organiza de acuerdo no sólo a una política autoritaria, sino también a partir de un diseño orientado a los intereses económicos. La Constitución de 1980 promueve y, por tanto, aumenta la privatización de servicios estatales, reduciendo aún más el gasto fiscal y la inversión en el sector público que resulta en el cierre de colegios y clínicas que contaban con este financiamiento. La destrucción de barrios tradicionales de clase trabajadora ubicados en el centro de Santiago y su consiguiente traslado a poblaciones creadas en la periferia señala una clara intención de homogenización de las urbes.
} 
de la economía neoliberal. Sin embargo, los dos rayados siguientes comunican una cierta desaprobación cínica de las modernizaciones características de este tipo de desarrollo. La destrucción de vida pública promovida por la dictadura se consolida por los mecanismos de alienación del mercado: se tipifica el encierre de la familia a la privacidad de la casa y prolifera el sentido de la alienación originaria a las ciudades del capitalismo integrado. Esta sensación es irónicamente inscrita en el muro, como intento de superarla a través de su difusión; se intenta establecer una conectividad a través del sentimiento compartido de alienación, o el impulso sencillo de anunciar en repugnancia. Frases como "LA CIUDAD NOS VOMITA" y "VIDA AJENA" figuran sobre los muros blancos que se extienden al lado de la carretera (Figuras 1 y 2). La situación de emergencia en la que se encuentran tales graffitis de leyenda está lejos de pertenecer a una ideología política, sin embargo, connota una suerte de disidencia desarticulada. Aquí el signo pierde la dimensión de la idealidad en que se elabora un concepto ideológico. Los recursos administrados saltan a la vista pública en un énfasis de la materialidad del mensaje. El contenido parece secundario a la audacia del formato de la pared en el espacio público, el acto de escribir vence a la palabra, la exteriorización de un algo es el centro de gravedad del gesto.

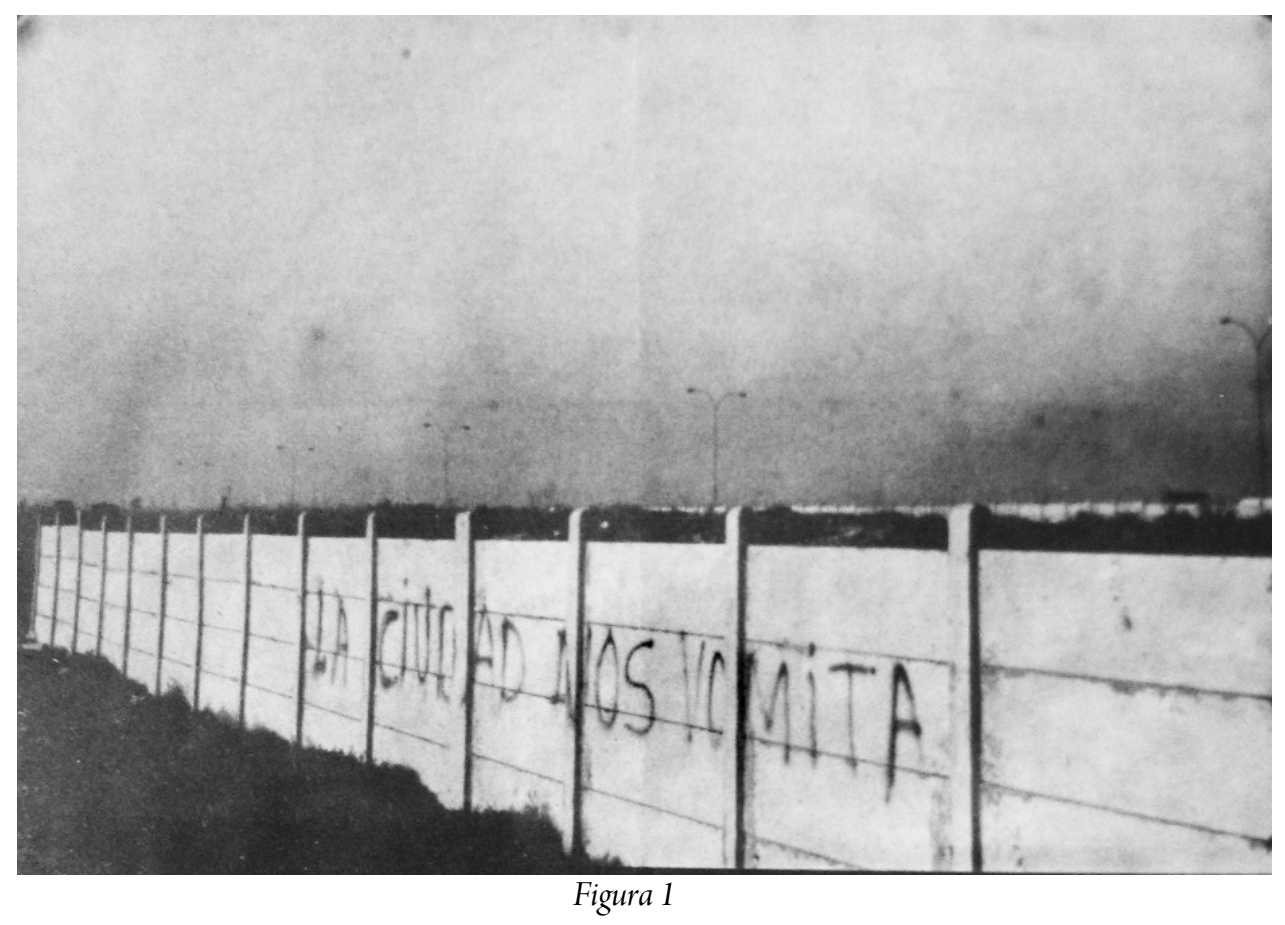




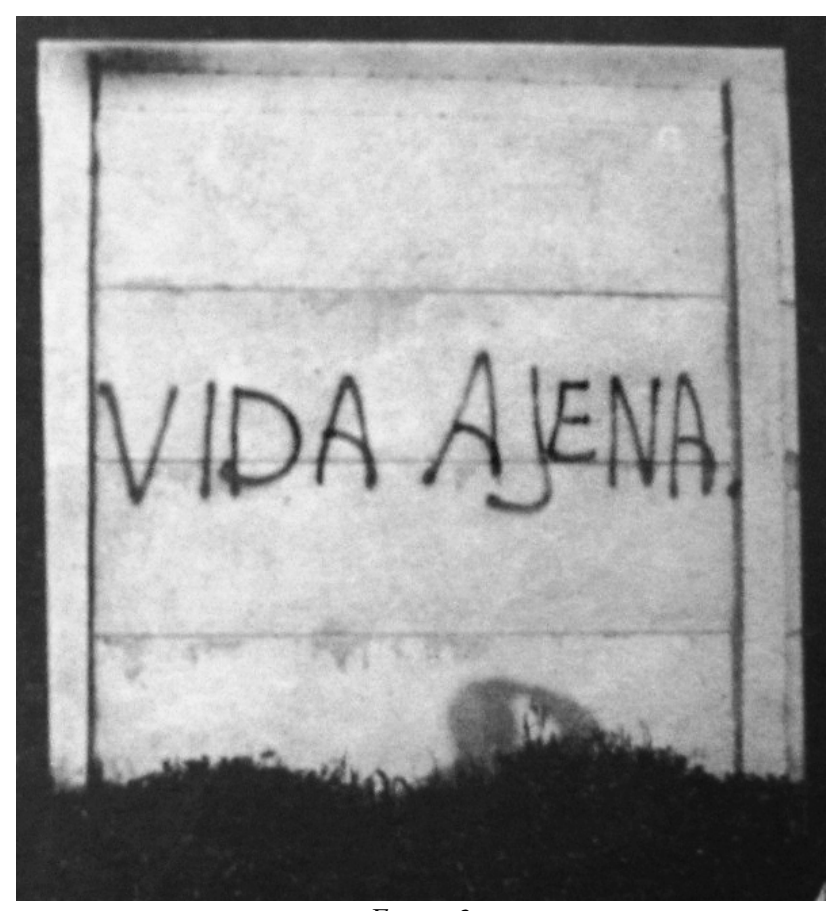

Figura 2

La nueva estrategia comunicativa cuestiona entonces la base de la comunicación misma, deconstruyendo los significados más razonables del lenguaje y enfatizando la productividad del mismo en vez de utilizarlo como un medio vacío. La palabra escrita con spray devuelve no sólo parte del paisaje urbano, sino también del diseño general de la imagen que traspasa lo literal de un mensaje como tal, invocando los juegos de palabra, la ironía y la comunicación negativa, pero sin embargo intencional. A veces los mensajes niegan hasta el objeto del propio mensaje, tal como en el rayado en el suelo: "TU NI SIQUIERA MERECES UN GRAFFITI" (Figura 3). Este juego de poder refleja la postura irónicamente rebelde y "ni ahí" ¿ ¿Quién es el tú anónimo? ¿Por qué exteriorizar un reclamo sin revelar el problema ni el culpable? Aquí el lenguaje pierde la cualidad de mensaje con fines concretos, lo prominente es la exteriorización de un malestar que reclama un lugar a la vista pública. Es una instancia en la cual se niega el valor de hacer sentido, generando un efecto vacío que devela la incapacidad de los modos representacionales tradicionales para efectuar cambios en el plano de lo real. Al mismo tiempo que esta inscripción se construye sobre el factor negativo comunicativo, por el hecho de no revelar el sujeto de su mensaje, niega la construcción de esta negatividad por rechazar la importancia de este sujeto. 


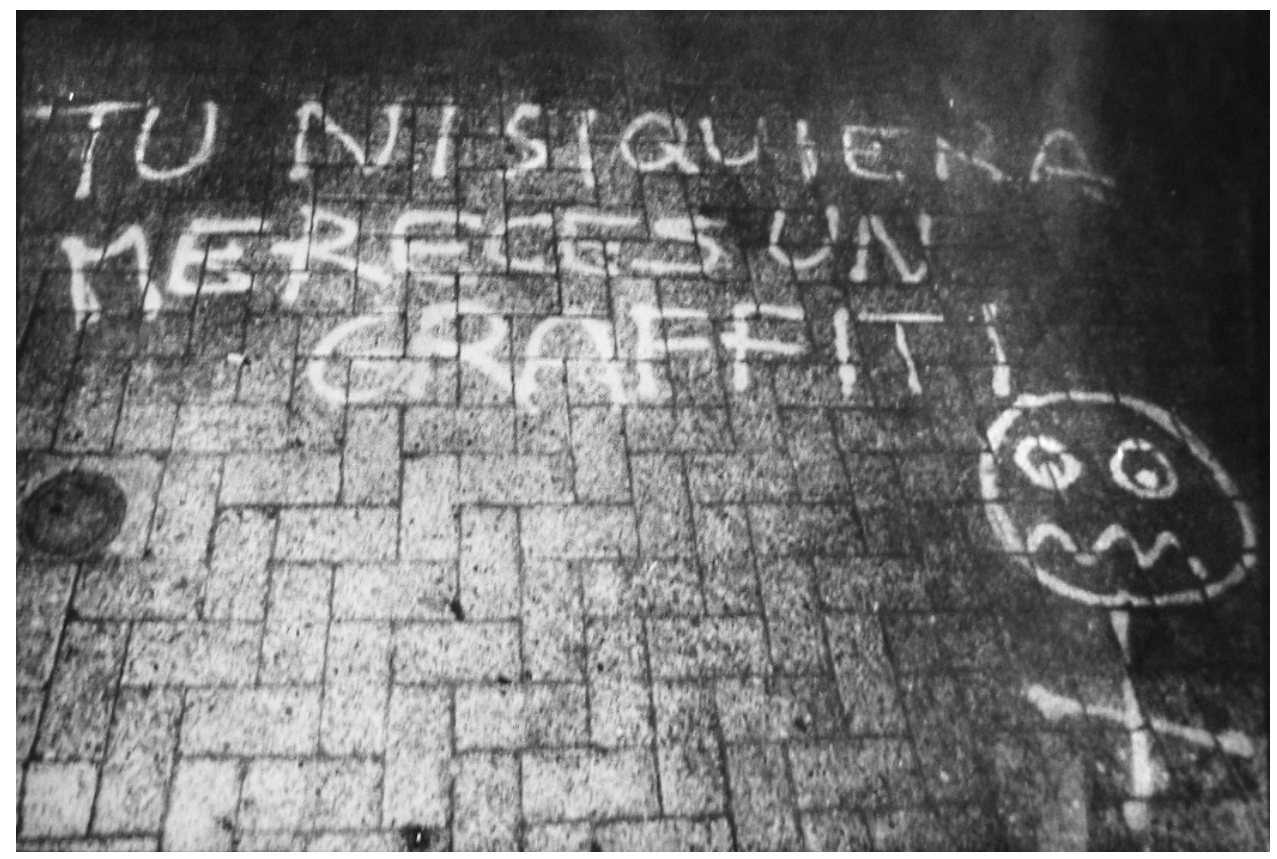

Figura 3

En el contexto de la dictadura, el gesto del rayado implica una transformación inmediata e indiscutible del lugar en cuestión. La estética de la urgencia que ofrece es una sustitución inmediata al cambio lento de una estructura política de participación inalcanzable. Además, la correlación negativa entre el acceso a un medio de comunicación y su capacidad de difusión está fomentada por los medios masivos, se hace entonces pertinente la búsqueda de nuevas estrategias de comunicación que se desarrollen a la vista pública. El mismo mercado neoliberal trae consigo las nuevas herramientas, como el spray, que posibilita la inscripción efectiva y rápida encima las superficies de la ciudad.

\section{Actores subculturales: en disidencia permanente con nosotros y los demás}

La exploración de las motivaciones y circunstancias identificatorias de los sujetos humanos, escritores del graffiti, es crucial para el entendimiento de la práctica y su impacto en la esfera social emergente de la época. Sólo en dos rayados particulares se pueden detectar unas claves hacia la identidad de estos actores efímeros, el mensaje: "QUE LE CAIGA UN RAYOS" pinta pura rabia y de nuevo el receptor designado de este mensaje está ausente (Figura 4). Este rayado porta también una firma, un aspecto rara vez incorporado a los graffiti de leyenda. Las palabras "CAÑA ALTAS" indica la relación 
con un estilo de zapatillas converse (en los ochenta, high tops), las cuales son propia a una estética punk. Mientras que no se puede identificar un autor o autora específica, se identifica esta escritura con una subcultura o comunidad estética emergente en estos tiempos. El rayado "PREFIERO EL CÁOS A ESTA SITUACIÓN TAN CHARCHA", toma sus letras de una canción de Mauricio Redolés, poeta y músico chileno quien circuló los terrenos de las fiestas ochenteras tales como El Trolley y Garage Internacional Matucana (Figura 5). El rayado cita una ideología anarquista y un aburrimiento generalizado.

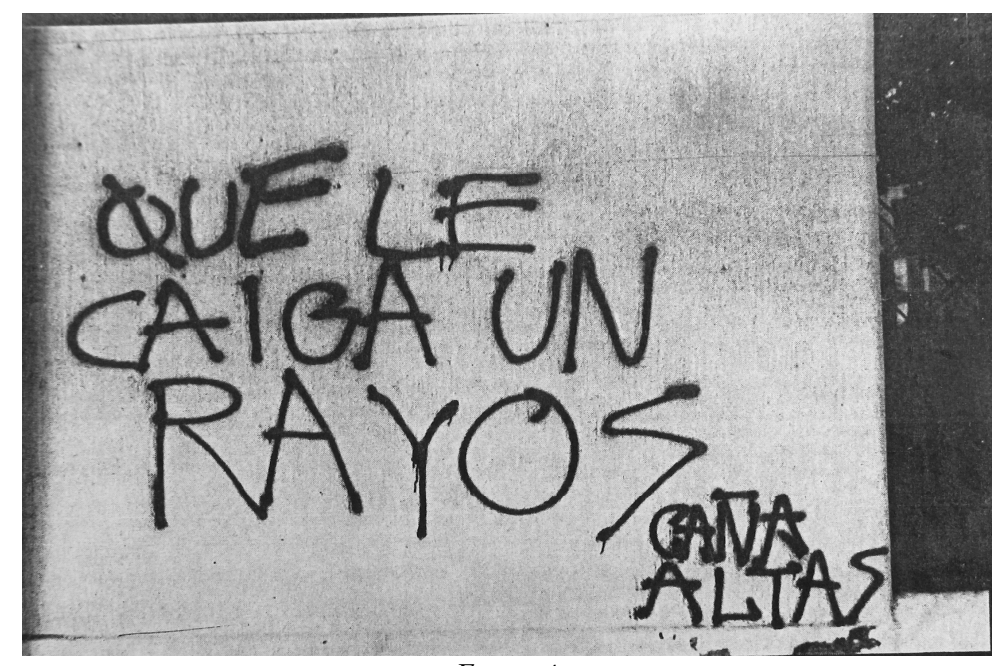

Figura 4

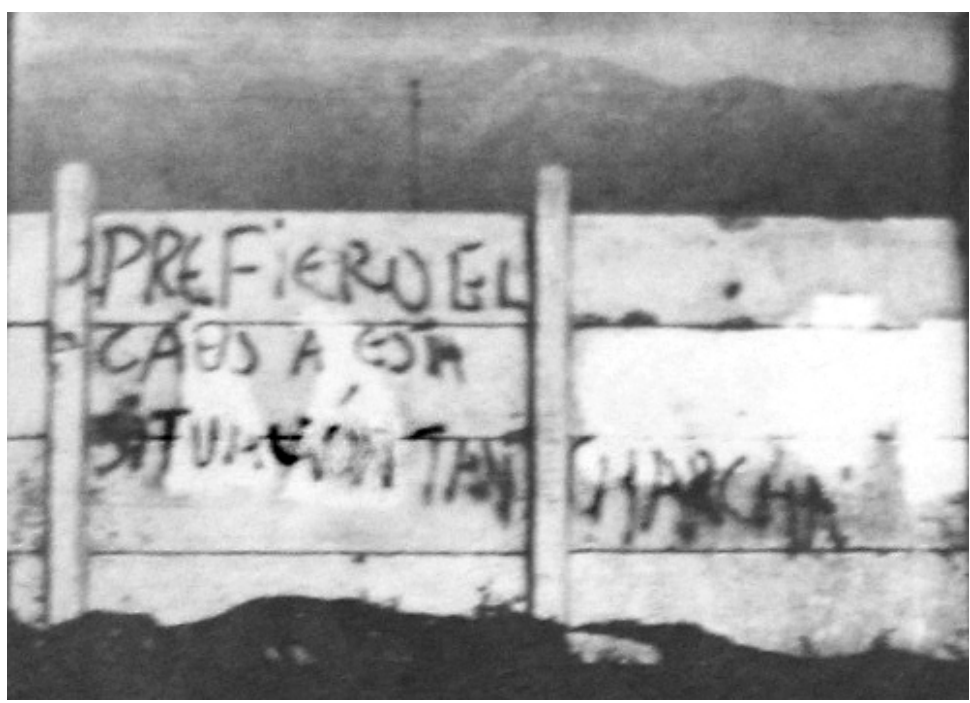

Figura 5 
Si bien la desinstitucionalización de la cultura ocurre con el golpe de estado inaugurando una ruptura de experiencia, el cómo concebir los códigos- la ruptura se profundiza poniendo en cuestión el valor mismo de la memoria en una sociedad que se llena de lo desechable. La experiencia de la dictadura empieza a variar drásticamente entre generaciones. Este distanciamiento se encarna por la introducción de productos culturales extranjeros tales como la música en inglés y luego el rock argentino. En su estudio sobre Buenos Aires, Claudia Kozak revela "la relación que se establece entre graffitis y música 'joven', este eje pasa en general en la Argentina por el rock y todos sus derivados” (2004, p. 38). El new wave fue el término que enmarcó indefinidamente a las subculturas jóvenes chilenas con influencias estilísticas importadas_incluyó, sin delimitaciones agrupaciones que escucharon la música pop, punk, pre-eléctrica y el heavy metal. A pesar de sus diferencias estéticas e ideológicas, lo que tenían en común estos grupos eclécticos fue la anunciación de su disidencia y/o diferencia a través de rituales de consumo resignificantes y la apropiación de estilos subculturales extranjeros que apuntó al desinterés creciente en el pasado nacional, marcado por un quiebre con sus formas culturales tales como el canto nuevo y la vestidura hippie. Mientras que estas estéticas se concretizan con la llegada de subculturas ya mediatizadas por el primer mundo, se les da un toque local por los protagonistas de su incorporación a este continente. Como resultado de su diferencia, estos jóvenes son víctimas de una represión uniformada por la policía tanto como por los gritos de "simples viejos". Parecen "marcianos" cuya forma de ser pervierte el orden regimentado por años de experiencia dictatorial (Birkner, 1986, p. 3).

Los nuevos estilos se reflejan públicamente no solo a través de su vestimenta, sino también en el gesto desafiante de rayar la pared. Su capacidad de señalar el desorden no se basa en la creación de otra jerarquía simbólica -trabajo de la oposición partidista-, sino en establecer una cierta autonomía respecto de antiguas pautas binarias de la representación. Para Sergio, peluquero estilo new wave, "al gobierno le conviene que nosotros estemos muertos en vez de vivos, porque nosotros no pescamos nada y eso es peligroso, cuando alguien no quiere hacer caso ni de lo negro ni de lo blanco, quiere decir que viene algo detrás de eso que es mucho más fuerte" (Birkner, 1986, p. 2). La mentalidad de "no pescar" se revela en la creación de mundos independientes, ambientes y circunstancias en las cuales se desarrollan valores propios a las subculturas. Estos procesos de territorialidad se elaboran a través de rituales sociales tales como la fiesta y los actos de creación colectiva en el espacio público. Estas nuevas formas de integración social emergen en el contexto de una carencia total de participación en estructuras macrosociales. Se recurre, entonces, a lo estético y a la espacialidad para resolver los problemas y contradicciones creados por la política autoritaria altamente controladora y la apertura irónica que proviene de su estructura económica. Para Gonzalo Rabanal, la solución reside en el alejamiento de 
políticas partidistas, el ex-militante del MIR se vuelve artista intervencionista de la calle. En una entrevista para el libro La era ochentera explica:

A mediados de los ochenta fuimos muchos los que nos aburrimos de la militancia; nos decepcionamos y nos rebelamos contra los jerarcas. Y empezamos a vivir con la idea del fracaso... empezó a ser un movimiento no contenido desde la consigna ni desde el panorama político. (2005, p. 236)

En otra entrevista Rabanal (2008) articula que "En verdad no nos planteamos como contra la dictadura sino que buscamos crear nuestro propio espacio". Esta relativa independencia, encajada en la mirada casual hacia el no-futuro, deja detrás la lucha de la generación de los padres, sin quitar su afinidad por la confrontación. Si bien los métodos de socialización bajo la dictadura utilizan los medios de difusión, la respuesta de los jóvenes disidentes fue utilizar el espacio público para la transmisión de sus (no)mensajes. Elaborando intervenciones del espacio público, unas tan simple como el rayado hasta otras de cualidad de instalaciones, como el colectivo Los Ánjeles Negros ${ }^{2}$ quienes tenían por objetivo "intervenir la prensa amarilla de esos tiempos...el plan funcionó bien y nos reímos del poder en ese momento, nos dieron duro, pero las cosas se hicieron ... esa fue nuestra vitrina de discurso, parodia y acidez" (Rabanal, 2008).

El nuevo objeto de la escritura en el espacio público se centra en el reflejo de una imagen identitaria, no relacionada a la firma de un grupo así clasificable, pero sin embargo representativa de inquietudes e intereses particulares. Por ejemplo, el rayado pronunciado en spray blanco, "MADONNA" cuyo mensaje de carácter de homenaje a la cantante diva de los ochenta se contextualiza por la inundación de la música en inglés ${ }^{3}$ (Figura 6). Mientras que este mensaje se podría referir a la connotación religiosa de la palabra, no es menor que en el año 1985 el EP Material Girl obtuvo el puesto numero uno en los ratings de radios chilenas. La inscripción abajo, "LAJA CAMPEON", parece ser escrito por la misma persona, siendo que la letra del escritor demuestra una similitud discordante al rayado de arriba. Se despliegan aquí dos elementos fundamentales de la identidad del escritor: la música contemporánea (o la religión), más el deporte. Desde la perspectiva de Armando Silva, "el sujeto se inscribe o dibuja sobre un muro para verse él mismo como imagen pública" (1987, p. 71). Pero si el sujeto escritor busca crear una imagen autorepresentativa que tendrá lugar en un imaginario colectivo, el formato interactivo en el cual se inscribe no le permite fijar su imagen bajo la pauta tradicional de la representación. En los pocos casos en los cuales se firman los rayados, se ocupan nombres

2 El Piano de Ramón Carnicer, Luger de Luxe, Los Huoman y Los Rififí son algunos, entre otros, de los que forman parte de la investigación más extensa sobre este tema.

3 En el año 1985 el EP Material Girl obtuvo el puesto numero uno en los ratings de radios nacionales. 
que normalmente no referencian directamente la identidad de los escritores. Además, el escenario donde se despliega la imagen está abierto a una gama de intervenciones e interpretaciones. Si bien el poder de representar señala una suerte de dominación ideológica, el uso del tag o el graffiti escapa de los marcos delimitadores que implican la comunicación de un mensaje literal.

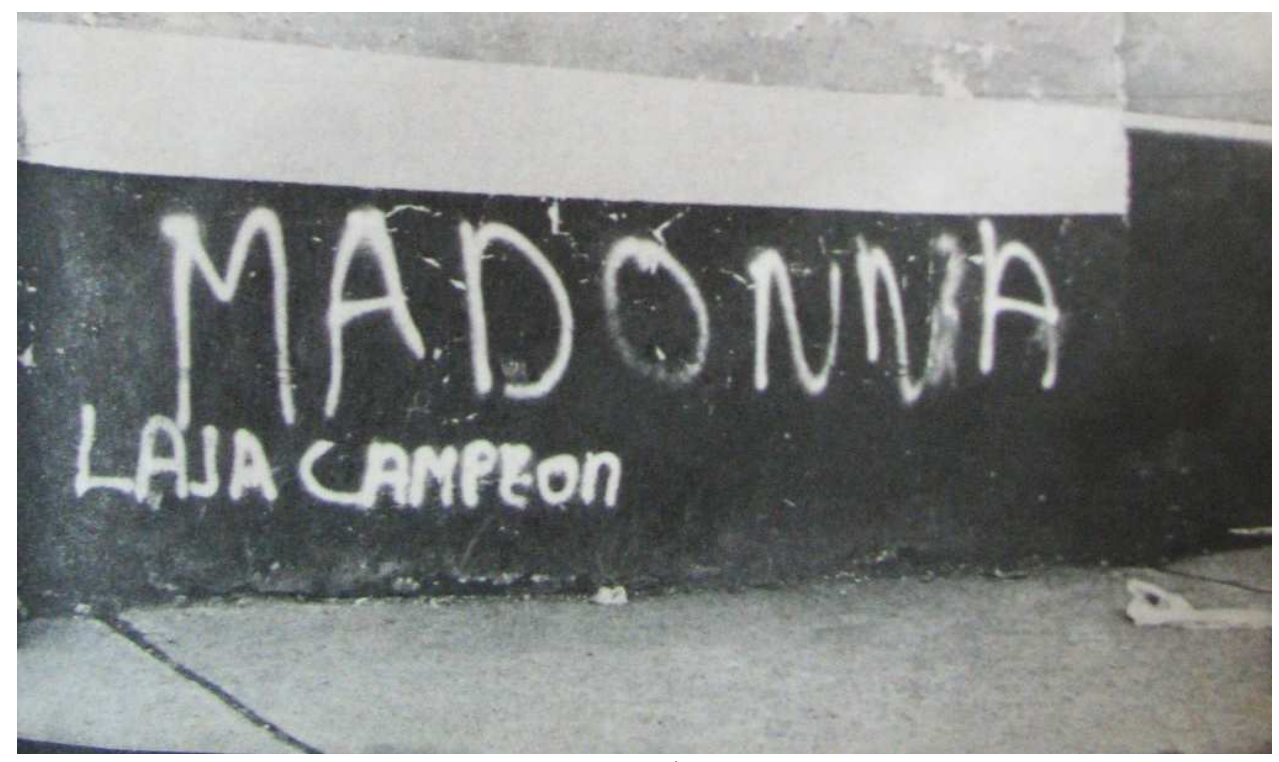

Figura 6

\section{No concluyentes}

Escribiendo acerca de Los Prisioneros en 1986, un periodista bajo el seudónimo L'Angelo Misterioso reproduce las letras cantadas por Jorge González a sus fans:

\footnotetext{
¡Latinoamérica es un pueblo al sur de Estados Unidos! - grita.

¡No sési ustedes pero nosotros no necesitamos banderas! — grita.

... ¿Qué es todo esto? ¿Un movimiento juvenil? ¿De dónde salió todo este público que parece tener una identidad colectiva ya definida y que corea ‘ $i$ o queremos representatividad!' al sonido de la guitarra eléctrica y la batería? (1986, p. 20)
}

En esta serie de declaraciones, el rechazo de consignas políticas partidistas y nacionales que surgen de las voces jóvenes de los ochenta, se relaciona con la posición de subyugados a la dominancia norteamericana. Los símbolos nacionales de pugnas políticas pasadas asumen otros significados para los jóvenes de una globalización temprana. La 
desideologización que ocurre con la diversificación de información y materialidades disponibles también se podría pensar en relación a un sentido de decepción hacia las alternativas políticas planteadas por la generación de sus padres, como un "mecanismo de protegerse”, en palabras de Pepe Moreno (2008). La bandera roja connota lo prohibido tanto como la sangre derramada en la derrota del proyecto nacional por construir el socialismo de forma democrática. El cuestionamiento del por qué de este fracaso se sigue por variadas respuestas surgidas de distintas posiciones ideológicas. A pesar de la gama de respuestas posibles, en este proceso de reflexión está siempre presente una fuerza violenta y sistemática que contaba con los recursos materiales de la nación más poderosa del planeta durante esos tiempos. De este aspecto no se habla mucho, sino que se siente su peso en la forma de una impotencia de poder decidir el momento y la dirección del propio imaginario social. Esta incapacidad se intenta solucionar a través del cambio inmediato de visualizar su propia palabra en el espacio público.

Como vemos en los rayados en la pared durante la década de los ochenta, emergieron pequeñas escrituras de disidencia y confusión relacionada a las transiciones culturales y condiciones políticas experimentadas en variadas formas por distintas generaciones. A pesar del poder expansivo de las formas culturales propagadas por el modelo neoliberal, Henri Lefebvre nos recuerda que siempre estarán presente las "objeciones y contradicciones que dificultan el cierre del circuito [ideológico]” (1991, p. 17). En el caso del gobierno militar en Chile, este concepto es particularmente relevante, la censura de la producción cultura nacional que soluciona a través de la importación, crea las condiciones de apropiación bajo las cuales la cultura está reconfigurada por actores jóvenes quienes miran no hacia el sueño norteamericano por la esperanza, sino a las subculturas venidas del norte que encarnan su propia crisis. Los graffitis evidencian que el objetivo ya no es establecerse como otra hegemonía posible, sino buscar salidas a las estructuras en vías de extinción.

\section{Referencias bibliográficas}

Birkner, C. (1986, abril). Punks: los hijos de Pinochet. La Bicicleta. Volumen VIII, №70. pp. 2-5.

Bourriaud, N. (2006). Estética relacional. Buenos Aires: Adriana Hidalgo Editora.

Contardo, O. y García, M. (2005). La era ochentera. Tevé, pop y under en el Chile de los ochenta. Santiago: Ediciones B.

Foster, H. (1996). The Return of the Real. Cambridge, Mass.: MIT Press.

Kozak, C. (2004). Contra la pared. Buenos Aires: Libros del Rojas.

Lefebvre, H. (1991). The Production of Space. Oxford: Blackwell.

Misterioso, L. (1986, agosto). No sé si ustedes pero nosotros no necesitamos banderas. La Bicicleta. Volumen VIII, Nº73.p. 30. 
Moreno, M.A. (2004, noviembre). Delincuencia visual para reivindicar la chilenidad. Los Ánjeles Negros (sic). Revista de Crítica Cultural. No29/30.p.35.

Moreno, José. (2008). Entrevista inédita.

Rabanal, Gonzalo. (2008). Entrevista inédita.

Rivera, A. (1982). Transformaciones culturales y movimiento artístico en el orden autoritario. Santiago de Chile: CENECA.

Silva, A. (1987). Punto de vista ciudadano: focalización visual y puesta en escena del

graffiti. Bogotá: Instituto Caro y Cuervo.

Žižek, S. (2003). Ideología. Un mapa de la cuestión. Buenos Aires: Verso.

\section{Fuentes de las imágenes}

Figura 1. "LA CIUDAD NOS VOMITA". En La Bicicleta, Volumen VII, No64, (octubre, 1985), p. 27.

Figura 2. "VIDA AJENA". En La Bicicleta, Volumen VII, Nº4, (octubre, 1985), p. 27.

Figura 3. "TU NI SIQUIERA MERECES UN GRAFFITI". En La Bicicleta, Volumen VIII, N67 (enero, 1986), p. 27.

Figura 4. "QUE LE CAIGA UN RAYOS”. En La Bicicleta, Volumen VIII, N70 (abril 1986), p. 27.

Figura 5. "PREFIERO EL CÁOS A ESTA SITUACIÓN TAN CHARCHA". En La

Bicicleta, Volumen VIII, N67 (enero 1986), p. 27.

Figura 6. "MADONNA LAJA CAMPEON". En La Bicicleta, Volumen VII, Nº5, (noviembre 1985), p. 27. 